\title{
Erratum
}

\section{Visuomotor interactions in responses of neurons in the middle and lateral suprasylvian cortices of the behaving cat}

\section{T.C.T. Yin and M. Greenwood}

Exp Brain Res (1992) 88:15-32

An unfortunate error occured in Fig. 5 on p. 19 of the above article: parts C and D were omitted. The correct figure is printed below:
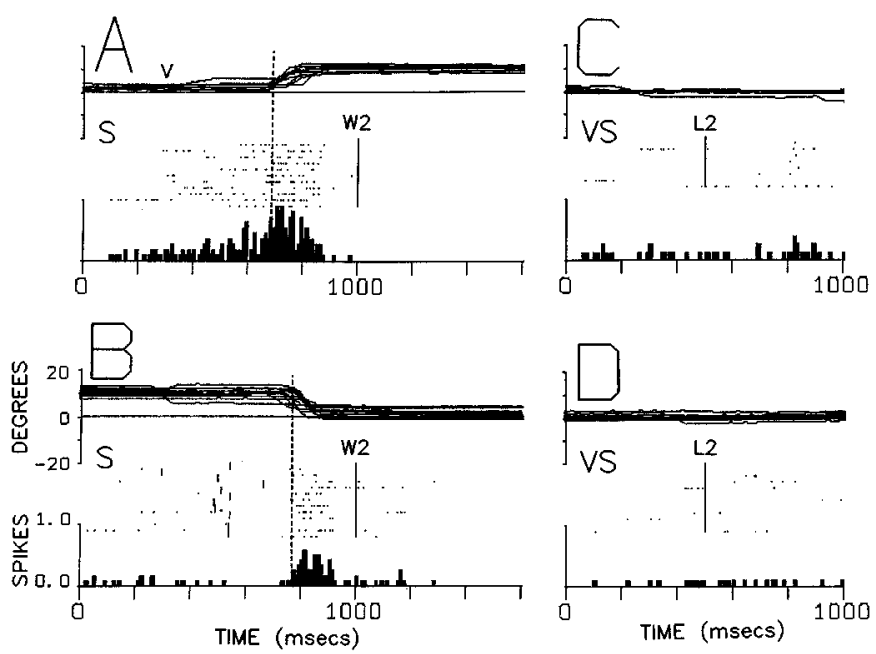

Fig. 5A-D. Saccade-related responses of a cell in the right MS to $\mathrm{S}$ trials with upward (A) and downward (B) saccades or to VS trials in which the test spot was moved downward (C) and upward (D) at saccadic velocities. The cell responded vigorously to the upward (A) and weakly to the downward (B) $12^{\circ}$ saccades. There was no visual response to a target moving at $500^{\circ} / \mathrm{s}$ over a $40^{\circ}$ range centered at $\left(0^{\circ}, 0^{\circ}\right)$ in the downward (C) or upward (D) direction. In $\mathbf{A}$ and $\mathbf{B}$ the events are synchronized to W2 at $1000 \mathrm{~ms}$ while in $\mathbf{C}$ and $\mathbf{D}$ they are synchronized to $\mathrm{L} 2$ at $500 \mathrm{~ms}$ 